\title{
Low-Cost 3D Imaging and Measurement Techniques for Documentation of Meram Masonry Arch Bridge in Turkey
}

\author{
Cihan Altuntas", Mustafa Emirhan Pehlivanlı, Selman Kurban \\ Department of Geomatics, Engineering Faculty, Selcuk University, Konya, Turkey \\ Email address: \\ caltuntas@selcuk.edu.tr (C. Altuntas) \\ ${ }^{*}$ Corresponding author \\ To cite this article: \\ Cihan Altuntas, Mustafa Emirhan Pehlivanl, Selman Kurban. Low-Cost 3D Imaging and Measurement Techniques for Documentation of \\ Meram Masonry Arch Bridge in Turkey. International Journal of Sensors and Sensor Networks. Vol. 5, No. 5, 2017, pp. 63-69. \\ doi: $10.11648 /$ j.ijssn.20170505.11
}

Received: October 6, 2017; Accepted: November 3, 2017; Published: December 25, 2017

\begin{abstract}
A lot of historical masonry arch bridges that have different architect and ages had been built in Turkey. Some of them have still been used, the others have been broken down due to natural or human effects. These bridges have complex shapes and difficult conditions to measuring. The close-range photogrammetry and photogrammetric dense point cloud methods enable to creating 3D model of a great number of historical bridges with fast, low-cost and high accuracy. The Meram Bridge is inside the Konya Metropolitan Municipality. It has still serve to public usage, today. It's dimensions are $29.5 \mathrm{~m}$ long and $4.5 \mathrm{~m}$ width, and has five arches. It has been restored many times so far. Though it has not been known when it was built, but it is probably belong to period of Seljuk Empire and Karamannid state during 13-14 century (BC). In this study, historical Meram bridges have been measured and 3D model was created. After given some literature review about the masonry arch bridges in Turkey, the 3D model of Meram Bridge was created. Its dimensions were given on the orthophoto images.
\end{abstract}

Keywords: Close-Range Photogrammetry, Dense Point Cloud, Masonry Arch Bridges, 3D Modelling, Image Based Modelling

\section{Introduction}

The role of the bridges is not only serve to passing from this side to other side. Also they include many cultural properties of the inhabit civilizations. The bridges reflect architecture, science and industrialization of the communities. Turkey has rich heritage such as historical construction, ancient city and stone masonry arch bridges due to their geographical location. The some of the bridges have still been served to public usage, the others are broken down due to the natural or human effects. The main reason of deterioration is natural disasters and overload transportation according to [1]. Konya region has also many stone arch bridges. Furthermore Meram district has about fourteen number of historical stone arch bridges [2].

The documentation of historical bridges is important for preserve and restoration of them. Three-dimensional (3D) digitalization is prevalent method for documentation and 3D modelling. There are many 3D measurement methods such as tacheometry, laser scanning, unmanned aerial vehicle, photogrammetry, dense point cloud etc. [3]. But a keypoint is the selection of the most appropriate method and algorithm able to achieve the desired accuracy and completeness. The photogrammetry and dense point cloud methods that enable fast and high accuracy measurement data are efficient way for documentation.

The photogrammetry can deliver comparable geometrical $3 \mathrm{D}$ results for many terrestrial and aerial applications. [4] introduced deformation measurement and 3D modelling of steel and masonry arch bridges that have different architectures. Also many measurement studies can be performed with low price $[4,5]$. The photogrammetry is the low-cost 3D modelling method relation to the other measurement methods [6]. On the other hand dense point cloud generation is increasingly utilized for a wide variety of applications. Photogrammetry and dense point cloud method are hand-held camera measurement methods. Thus complex shapes of architectural heritages like masonry arch bridges can be completely measured by these methods. In this study, 
historical masonry arch Meram Bridge had been measured by photogrammetry and dense point cloud methods for 3D modelling and documentation. In addition, its dimensions and visualizations from different point of view were given.

\section{Study Area: Meram Bridge}

The Meram Bridge is inside the district of Meram in Konya Metropolitan Municipality (Figure 1). It has served to public usage, today. Its dimensions are $29.5 \mathrm{~m}$ long and $4.5 \mathrm{~m}$ width, and has five arches. The middle arch is a little bigger than the others. The bridge has slope from middle to sides. It was built masonry arch stones as coherent to its around structures like bath, mosque and recreation facilities. It has been restored many times so far. The concrete has been built around the foot between the arches to protecting from a large flow. It is not known when it was build, but it was probably built to period of Seljuk Empire and Karamannid state at 1314 century (BC). Today, it has been used for passing the pedestrians only.

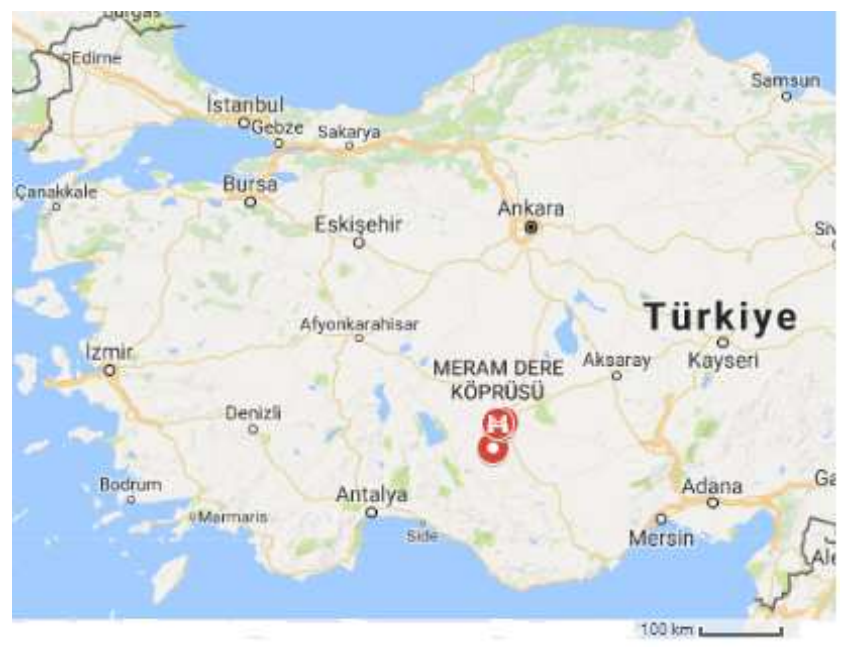

Figure 1. Location of Meram Bridge (Google maps).

\section{Methods}

\subsection{Photogrammetric Measurement}

The photogrammetry creates 3D measurement data from stereoscopic images. It is capable to get high accuracy measurement. It has been used for $3 \mathrm{D}$ measurement and modelling of small objects or large terrains for many years. The basic steps on photogrammetric measurement are camera calibration, image recording and $3 \mathrm{D}$ data acquisition $[7,8]$. The camera calibration is computation of inner orientation parameters that includes the principal point coordinates $\left(x_{o}\right.$, $\left.y_{o}\right)$, focal length $(c)$ and distortion parameters $\left(K_{1}, K_{2}, P_{1}, P_{2}\right)$. The calibration is made out with the images captured from different point of view of the special test grid [9].

The stereoscopic images are taken from different point of view of the same area. The measurement accuracy is direct related to base length $(b)$ between camera stations and imaging distance $(h)$. The ratio of $b / h$ should be close to 1 to get high accuracy by the photogrammetric evaluation.

The epipolar geometry must be realized to getting 3D measurement data from the stereoscopic images [10]. The epipolar geometry defines that the measured object point, camera projection centres and image points from the stereoscopic images have must the same plane. The relationship between object point and its image point has been expressed with the collinearity conditions. The collinearity condition must be realized at least five conjugate points to getting the epipolar geometry.

\subsection{Dense Image Matching}

Dense point cloud has been created from stereoscopic images as automatically [11]. The main steps on creation of dense point cloud are 1) keypoint detection, 2) structure from motion and 3) creation of point cloud.

At the first step, the SIFT, ASIFT, SURF and similar other operators are used to detecting the keypoints from the images. These operators find keypoints without affected from scale, rotation and brightness of the images. The second step is detection the relative position of the images by matching the similar keypoints from all the images. Considering a simple image pair, the disparity (or parallax, i. e. the horizontal motion) is inversely proportional to the distance cameraobject. The automated measurement of such disparity by establishing dense and accurate image correspondences is challenging task [12]. The matching results are in general sparse point clouds which are then used as seeds to grow additional matches. Nowadays all the algorithms focus on dense reconstructions using stereo or multi view approaches.

\subsection{Data Acquisition}

The photogrammetric images were taken by Canon PowerShot A2200 digital camera (4320x3240 pixel arrays). The camera calibration parameters were estimated as $f=5.1232 \mathrm{~mm}, x_{o}=3.1692 \mathrm{~mm}, y_{o}=2.3538 \mathrm{~mm}, K 1=1.756 \mathrm{e}-003$, $K 2=-2.316 \mathrm{e}-005, P 1=-1.041 \mathrm{e}-003, P 2=7.043 \mathrm{e}-004$. On the other hand, the images for creating dense point cloud were taken by Canon EOS 100D camera (5184x3456 pixel arrays). Their calibration parameters were estimated as $f=18 \mathrm{~mm}$, $K 1=-0.174193, \quad K 2=0.173295, \quad P 1=0.00065675, \quad P 2=-$ 0.000430506 .

The control points were measured on the bridge to make measurements based on georeference coordinate frame. A theodolite Topcon GPT-3007N which allowed measuring control points 3-D coordinates thanks to the integrated reflectorless rangefinder was employed to this task. Total 70 control points were measured on surfaces of the bridge.

\section{Results}

\subsection{Photogrammetric Results}

The Photomodeler software had been used for the photogrammetric evaluation [13]. After the images were uploaded to the software, characteristic details of the bridge were digitized with line from the stereoscopic images (Figure 
2). The bridge was measured by evaluating of 28 images with 70 control points. The object points were measured with maximum residuals of $3.99 \mathrm{~cm}$ (Figure 3 ). Then image texture data were mapped onto the created wireframe 3D model (Figure 4). In addition object dimensions were measured from created orthophoto images (Figure 5).
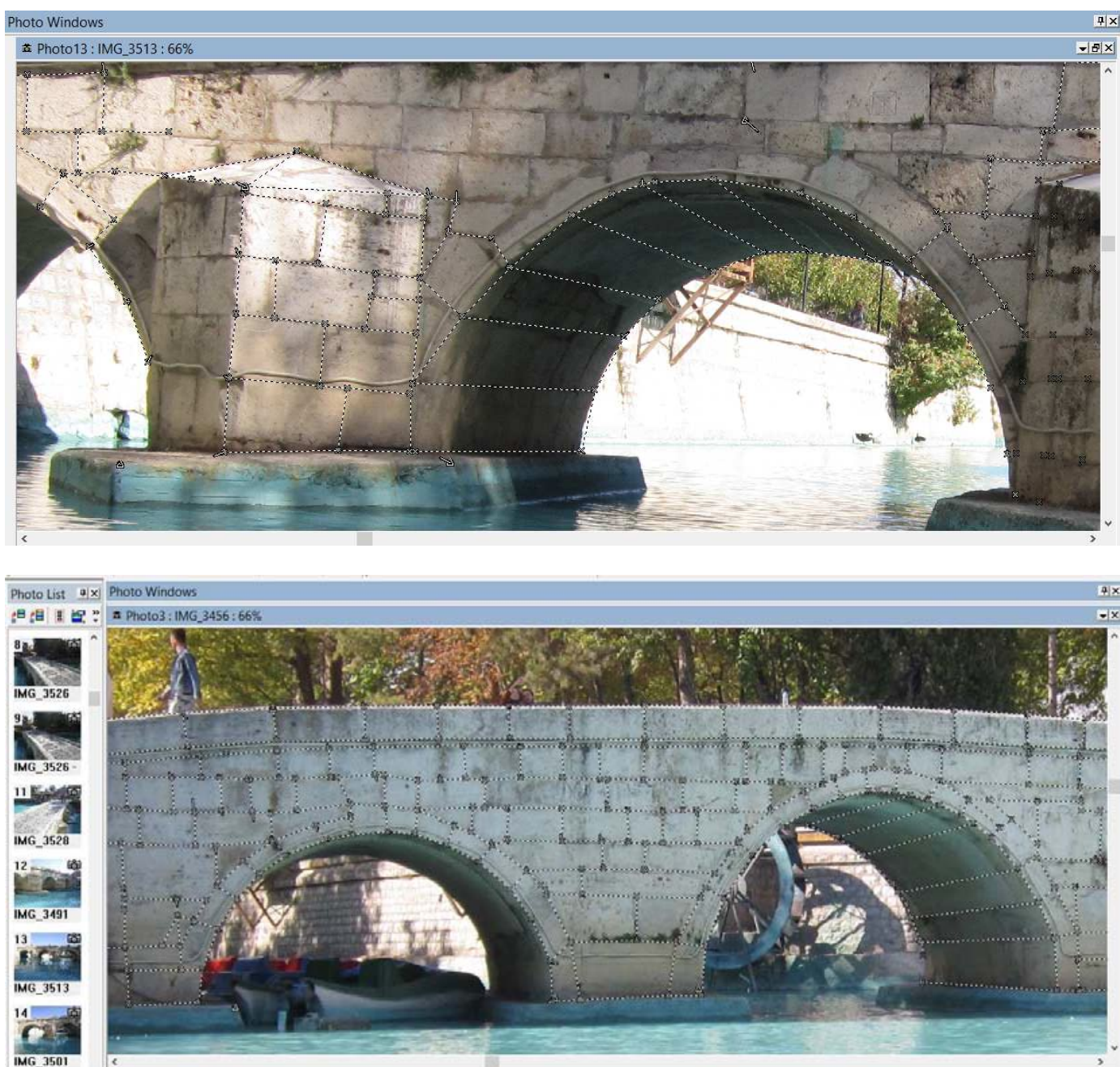

Figure 2. The photogrammetric evaluation of the Meram Bridge.

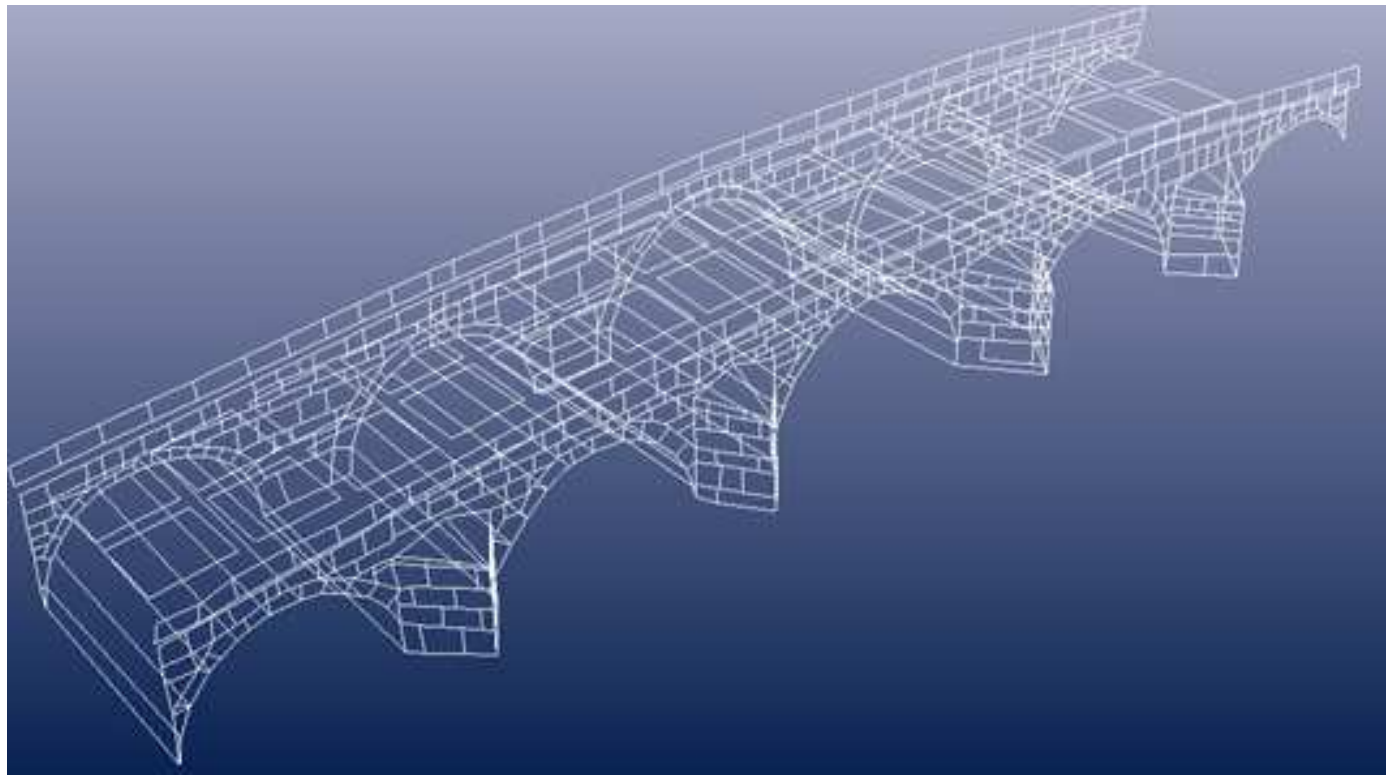




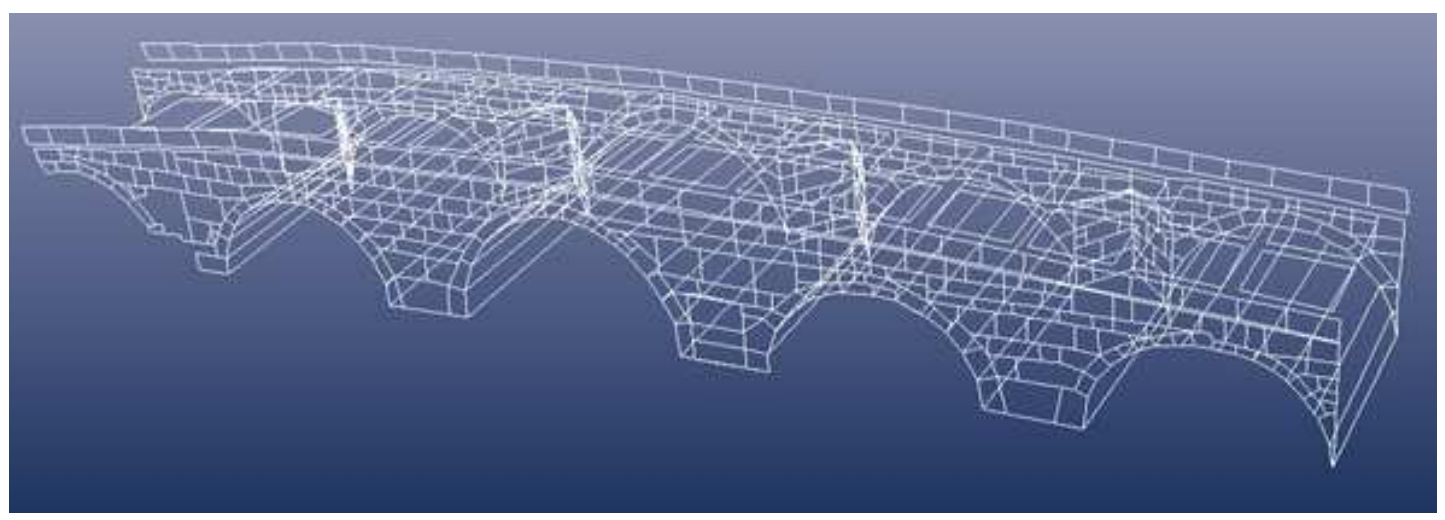

b)

Figure 3. Wireframe 3D model created with photogrammetric process. a) Upstream side, b) downstream side.
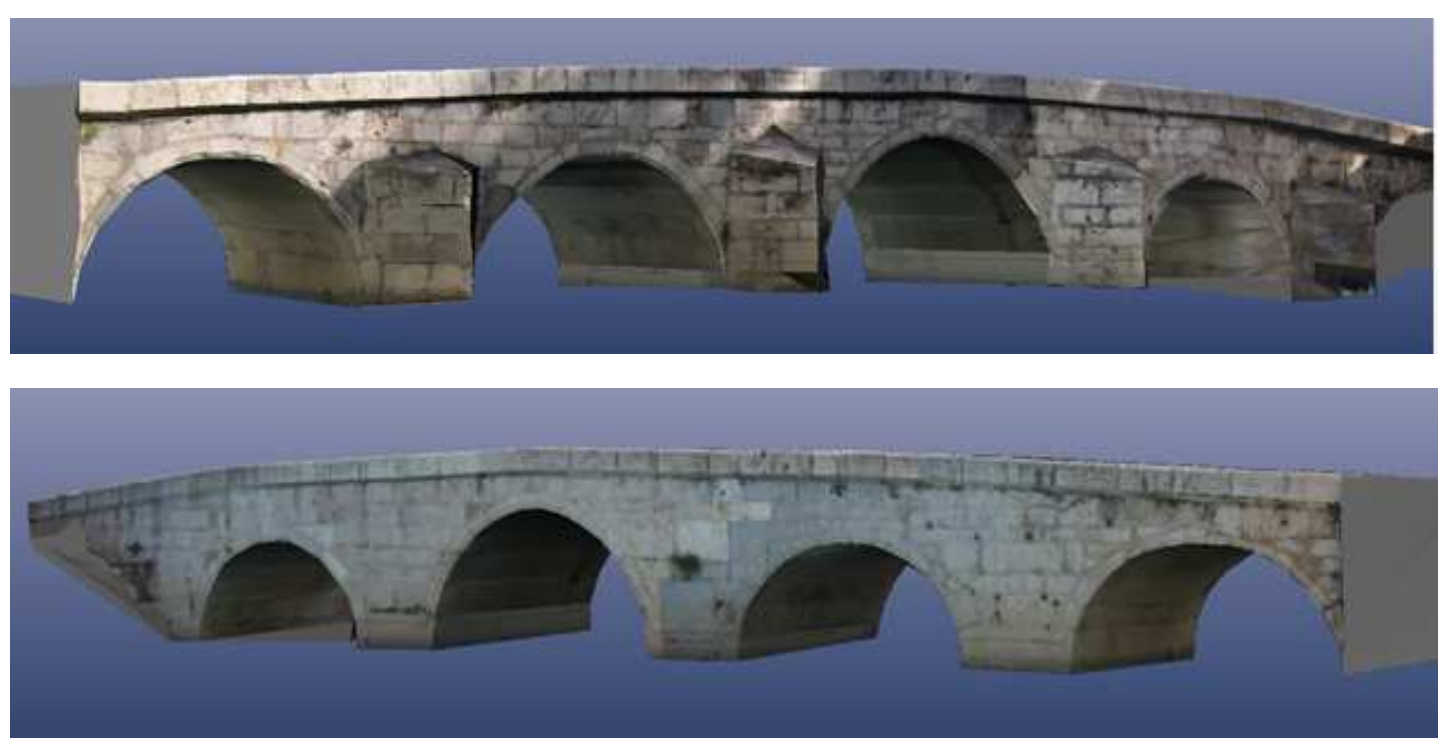

Figure 4. Texture mapped 3D model. Upstream side (above), downstream side (below).

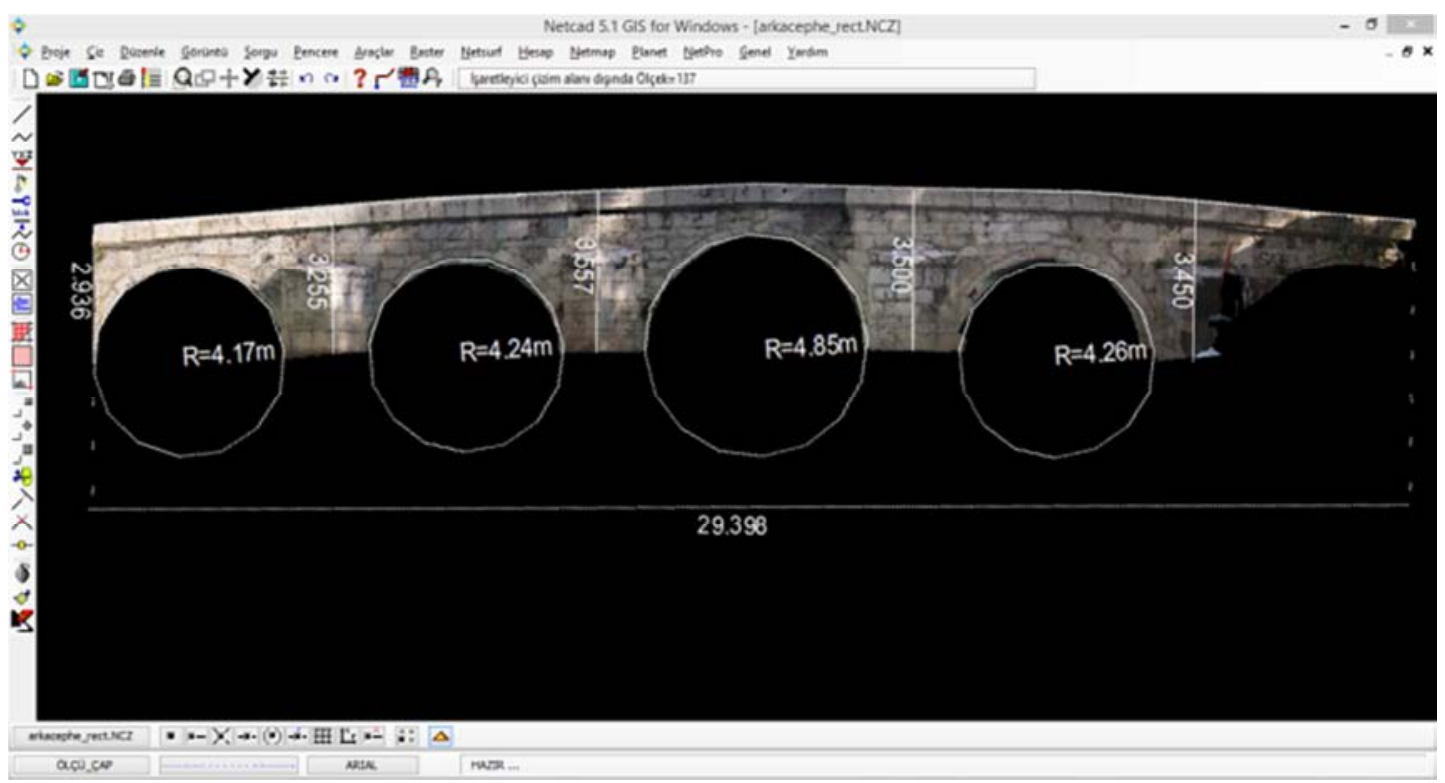




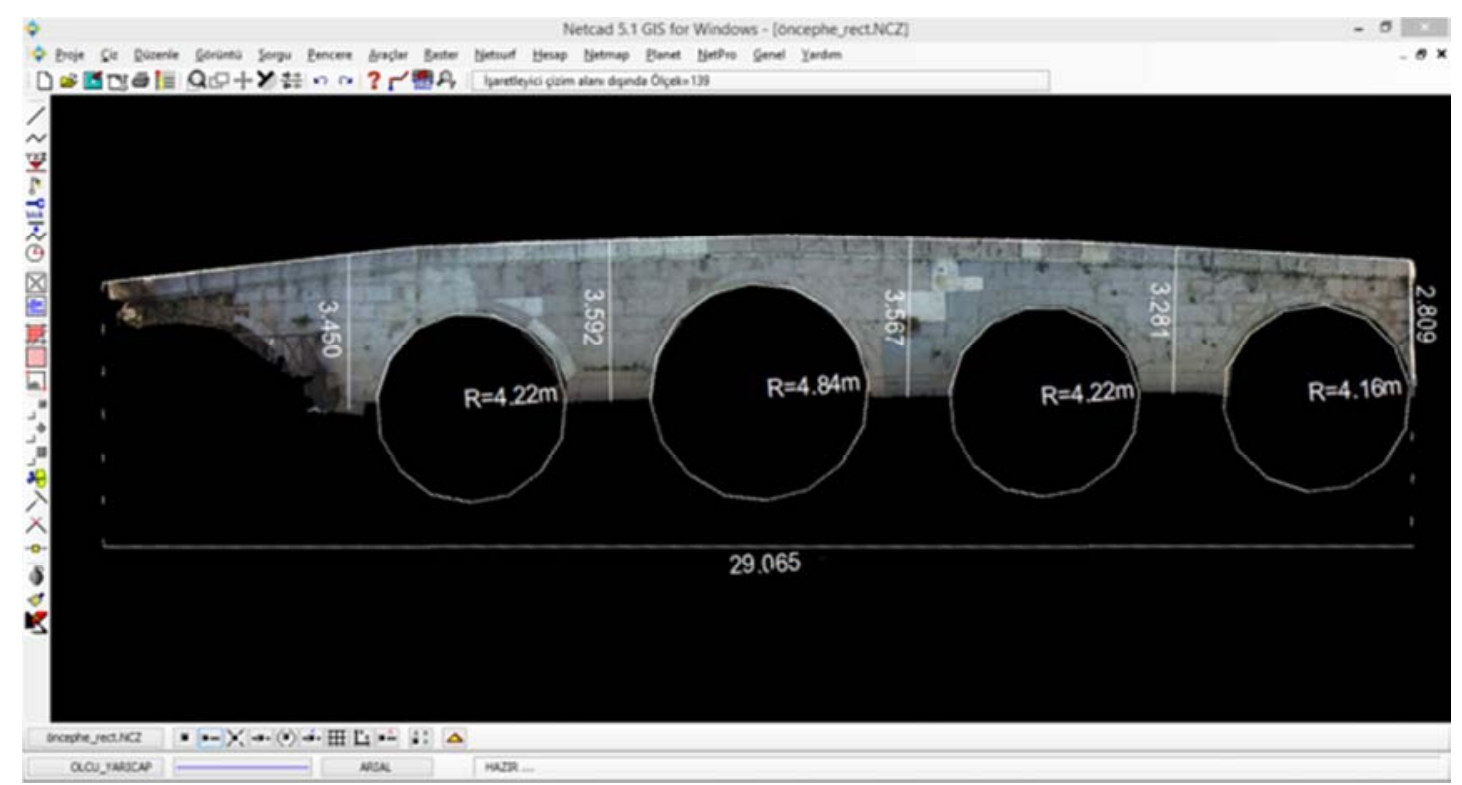

Figure 5. Orthophoto images from the side of upstream (above) and downstream (below).

\subsection{Dense Point Cloud}

The current photogrammetry softwares are capable to creating dense point cloud form stereoscopic images. In this study, dense point cloud had been generated using Photoscan software [14]. The Photoscan software has been used in many $3 \mathrm{D}$ modelling project so far. It is user friendly and high accuracy. 189 images of the bridge were used to creating dense point cloud. The bridge was imaged as overlap with many frames (Figure 6).

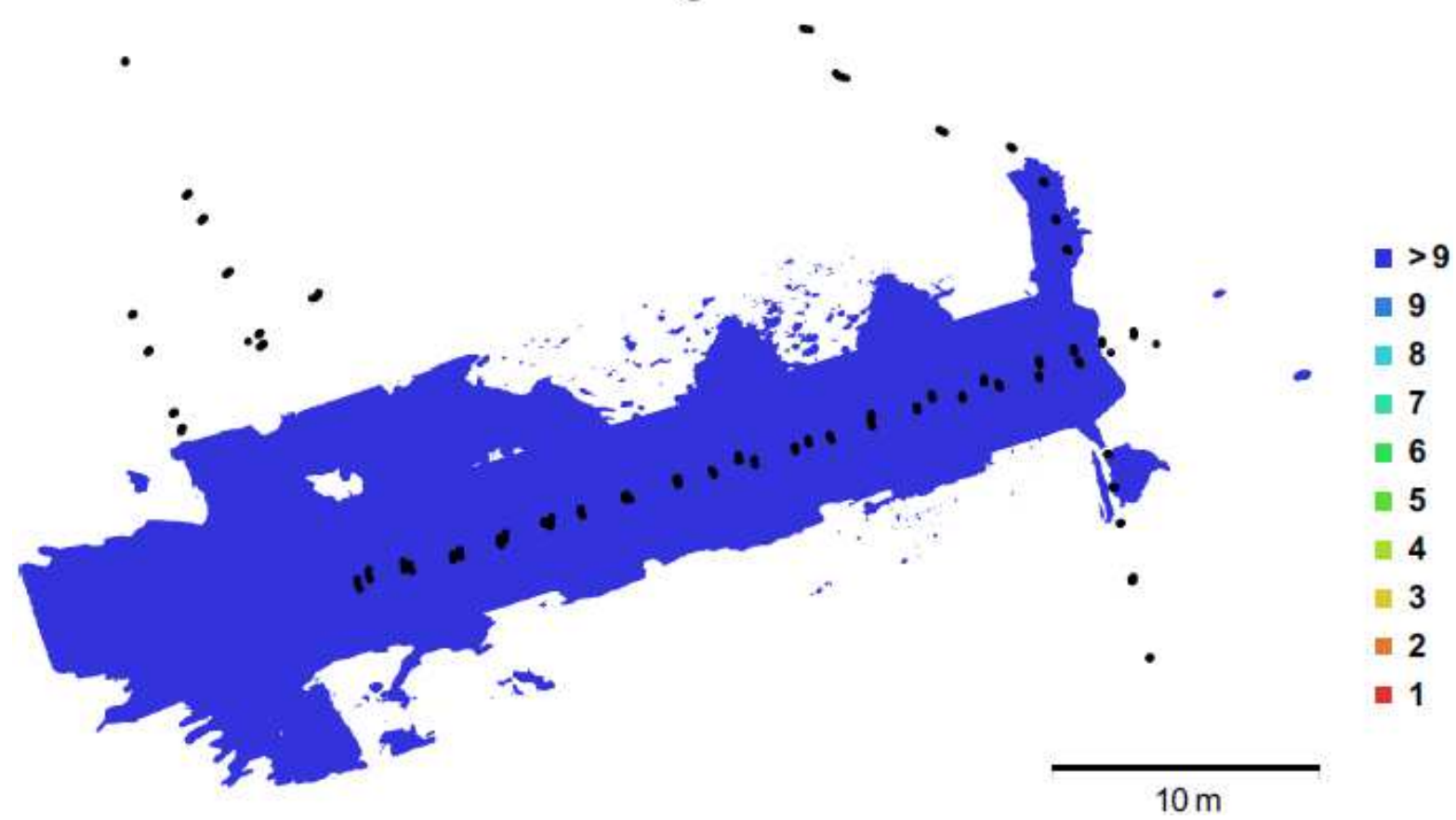

Figure 6. Map of image overlap and camera locations.

All the images are simultaneously processed to get point cloud. Initially, sparse point cloud is created from the keypoints then dense point cloud was created. Total 16629595 points were measured in two hours. The resolution is $5.35 \mathrm{~mm} /$ pix and point density is 3.5 points $/ \mathrm{cm}^{2}$ (Figure 7). Digital elevation model was also generated from the dense point cloud data (Figure 8). 

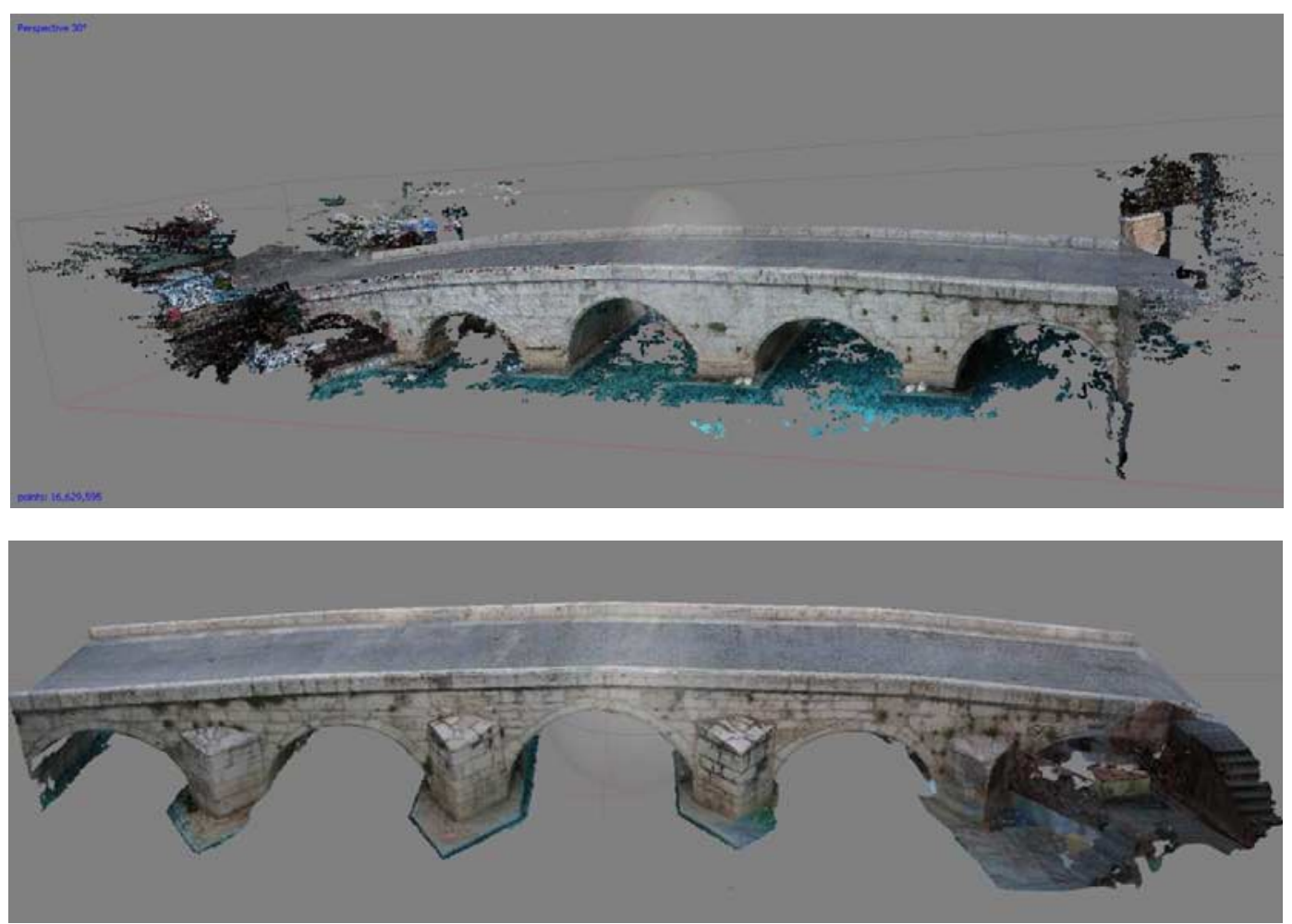

Figure 7. Dense point cloud model created by Photoscan.

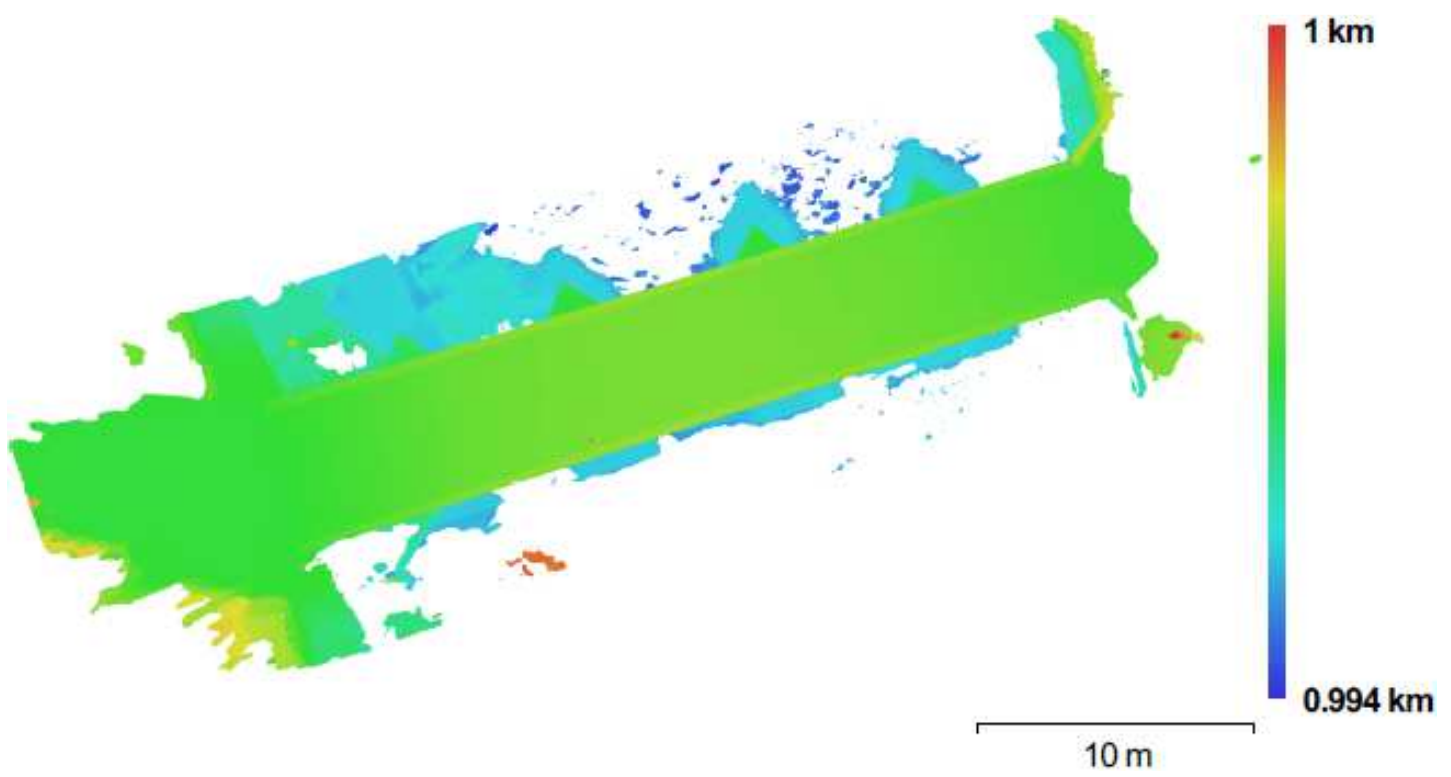

Figure 8. Digital Elevation Model.

Furthermore the dense point cloud model was registered to georeferenced coordinate frame by using six control points. Thereby, the photogrammetric and dense point cloud 3D model have been formed in the same coordinate frame.

\section{Discussion}

The photogrammetry and dense point cloud method use stereoscopic images for creation 3D model. But dense point cloud method uses more images than photogrammetry to building occlusion free 3D model. The scale of the model is defined by the control points on both methods. The ratio of distances from the model and the object can also be used for defining the scale.

The photogrammetry needs manual selection of conjugate points from the images for orientation and measurement. Thus the process takes more time than dense point cloud. However all the processes on dense point cloud are carried out by automatically. The number of measured object points are 4180 and 16629595 for photogrammetry and dense point cloud respectively. The complex shapes can be imaged by dense point cloud thanks to huge measurement data. Though 
dense point cloud model was created in 2 days, photogrammetric model was created in 25 days (Table 1).

The base/height ratio affects the accuracy of photogrammetric measurement. It should be about 1 for high accuracy measurement. But this condition was not realized every time because difficulties on taking the images. Thus all the image parameters had been computed by the same constraints with bundle adjustment. The points were measured with root mean square of $3.99 \mathrm{~cm}$. On the other hand dense point cloud method needs more image without consideration ratio of base/height. In fact the base lengths between arbitrary stereoscopic images should be very short in this case.

The both methods need computation the camera calibration parameters so as to get high accuracy results. Dense image matching (dense point cloud) as distinct from the photogrammetry estimates the camera calibration parameters automatically during the computation of dense point cloud.

Table 1. The review of $3 D$ modelling results by photogrammetry and dense point cloud methods.

\begin{tabular}{|c|c|c|c|c|c|}
\hline \multirow{2}{*}{ Methods } & \multicolumn{2}{|c|}{ Data acquisition } & \multicolumn{2}{|c|}{ Data processes } & \multirow{2}{*}{$\begin{array}{l}\text { 3D model } \\
\text { Points\#/ }\end{array}$} \\
\hline & Time & Image\# & Time & High labour & \\
\hline Photogrammetry & 3 hours & 28 & 25 days & Yes & 4180/very low \\
\hline Dense point cloud & 4 hours & 189 & 2 days & No & $16629595 /$ high density \\
\hline
\end{tabular}

\section{Conclusion}

The historical structures have complex shapes and sometimes it is very hard to imaging all their surfaces. However they have to be imaged for documentation of all their shapes. On the other hand, it is important that the instrument which will be used for imaging and modelling should be affordable and available. Also the modelling processes should be fast. According to result of this study, photogrammetry and dense point cloud are low cost measurement method for cultural heritage like masonry arch bridge. Dense point cloud method is much faster than photogrammetry. Moreover it is able to getting high density data in a short time with respect to the photogrammetry.

\section{References}

[1] A. Ural, Ş. Oruç, A. Doğangün and Ö. İ. Tuluk, 2008. Turkish Historicfal Arc Bridges and Their Deteriorations and Failures, Engineering Failure Analysis 15 (1-2): 43-53.

[2] Duran, R., 2008. Tarihi Konya köprüleri (Meram İlçesi), XII. Ortaçağ Türk Dönemi Kazıları ve Sanat Tarihi Sempozyumu. 15-17 Ekim, Çanakkale, Çanakkale Onsekiz Mart Üniversitesi Yayınları No: 98, 154-165.

[3] M. Scaioni, R. Perko and M. R. Veronez, 2014. Applications of Surveying in Land Management, Earth Science Informatics 7 (2): 69-70.

[4] R. Jiang, D. V. Jauregui and K. R. White, 2008. Close-Range Photogrammetry Applications in Bridge Measurement: Literature Review, Measurement 41 (8): 823-834.

[5] J., Albert, H. G. Maas, A. Schade and W. Schwarz, 2002. Pilot
Studies on Photogrammetric Bridge Deformation Measurement, Proceedings of the Second IAG Commission IV Symposium on Geodesy for Geotechnical and Structural Engineering, Berlin Germany, May 21-24, 7 pages.

[6] J. Valenca, E. Julio and H. Araujo, 2008. Application of Photogrammetry to Bridge Measurement, 12th International Conference on Structural Faults and Repair, Edinburgh, GB, June 10-12, pp. 1-11.

[7] Altuntas, C., 2013. Keypoint based automatic image orientation and skew investigation on tie points, Kybernetes 42 (3): 506-520.

[8] Kraus, K. 2007. Photogrammetry: Geometry from Images and Laser Scans, Walter de Gruyter, Berlin.

[9] Remondino, F., Ressl, C. 2006. Overview and experiences in automated markerless image orientation, The International Archives of the Photogrammetry, Remote Sensing and Spatial Information Sciences (IAPRS), Vol. 36, Part 3.

[10] Hartley, R. I., Zisserman, A. 2004. Multiple View Geometry in Computer Vision, 2nd ed., Cambridge University Press, Cambridge.

[11] Brazetti, L., Scaioni, M., Remondino, F. 2010. Orientation and 3D modelling from markerless terrestrial images: combining accuracy with automated. The Photogrammetric Record 25 (132): 356-381.

[12] F. Remondino, M. G. Spera, E. Nocerino, F. Menna, F. Nex and S. G. Barsanti, 2013. Dense Image Matching: Comparisons and Analyses, Digital Heritage International Congress (Digital Heritage), IEEE, 1: pp. 47-54.

[13] Eos Systems Inc., 2016. Photomodeler, http://www.photomodeler.com/products/modeler/ default.html [Accessed on 03 Nov, 2016].

[14] Agisoft, 2017. Photoscan Professional (Version 1.3.2.4205). 